\title{
IMPREGNAÇÃO DE NANOPARTÍCULAS DE ÓXIDO DE COBRE POR MÉTODO VERDE SOBRE CARVÃO ATIVADO PARA TRATAMENTO DE ÁGUA
}

\author{
J. PETERNELA ${ }^{1 *}$, L. NISHI', M. F. SILVA ${ }^{1}$, M. F. VIEIRA ${ }^{1}$, R. BERGAMASCO ${ }^{1}$, A. M. S. \\ VIEIRA $^{2}$
}

${ }^{1}$ Universidade Estadual de Maringá, Departamento de Pós Graduação em Engenharia Química ${ }^{2}$ Universidade Estadual de Maringá, Departamento de Pós Graduação em Engenharia de Alimentos *e-mail: josiane_peternela@hotmail.com

\begin{abstract}
RESUMO
Um dos métodos de obtenção de nanopartículas é a síntese verde, baseado na síntese por redução química, que utiliza componentes obtidos a partir de extratos de plantas, os quais servem como agentes redutores e/ou estabilizantes. Este trabalho teve o propósito de desenvolver um processo de impregnação de nanopartículas de cobre em carvão ativado pelo método verde, utilizando extrato de folhas de romã. Foram preparados carvões impregnados com $0,5 \%, 1 \%$ e $1,5 \%$ de $\mathrm{Cu}$ utilizando carvão ativado granular, sulfato de cobre e extrato de folhas de romã a $60 \mathrm{~g} / \mathrm{L}$. Agitou-se o carvão, o extrato e a solução de sulfato de cobre em shaker e secou-se o material em estufa a $50^{\circ} \mathrm{C}$. Realizouse as análises de caracterização necessárias. Através da análise de MEV pode-se observar que a estrutura superficial do carvão ativado permaneceu porosa, apresentando partículas em sua superfície, já a de MET mostrou uma matriz carbonácea acinzentada com partículas de coloração mais escura, características de partículas metálicas. O espectro de EDS detectou a presença do elemento cobre em todas as amostras produzidas, o que não ocorreu com o carvão puro. No método de BET foi constatado que os carvões produzidos apresentaram superfícies predominantemente microporosas, enquanto que no DRX foram observados picos referentes a materiais cristalinos sobre a superfície do carvão em angulações características de compostos de cobre, demonstrando que o método verde de redução e impregnação desenvolvido foi eficiente para obtenção do material proposto.
\end{abstract}

\section{INTRODUÇÃO}

Atualmente, a nanotecnologia tem apresentado aplicações em diversos campos da ciência e tecnologia, desde a medicina, bens de consumo, eletrônicos, comunicações e informática, até às aplicações ambientais, fontes de eficiência energética, agricultura, purificação de água, produtos têxteis, indústria aeroespacial, entre muitos outros (DIZAJ et al., 2014; FERREIRA, CEMLYNJONES e CORDEIRO, 2013). Geralmente, as nanopartículas possuem propriedades diferentes em comparação com o mesmo material em escala macro, devido ao fato de que a relação superfície/volume das nanopartículas aumenta consideravelmente com a diminuição do tamanho de partícula (DIZAJ et al., 2014).

As nanopartículas de óxido de cobre são de grande interesse tecnológico devido à suas propriedades físicas e químicas. Podem ser aplicadas em supercondutores de alta temperatura, catalisadores, baterias, sensores de gás, células de conversão de energia solar (CHANG et al., 2012) e utilizadas como 
agente antibacteriano, de baixo custo e baixa toxicidade (TAN et al., 2010).

Existem vários métodos de síntese de nanopartículas de cobre, como redução química (LIU E BANDO, 2003), redução térmica (DHAS, RAJ E GEDANKEN, 1998), métodos de radiação (LIPPMANN E SCHNEIDER, 2000), método dos vapores metálicos (VITULLI et al., 2002) e métodos eletroquímicos (CARNES et al., 2002). No entanto, várias limitações e desvantagens são apresentadas nestes métodos que geralmente requerem equipamentos especiais ou alta energia, implicando em um alto custo. As substâncias químicas envolvidas durante estes processos são tóxicas, corrosivas e inflamáveis, como $\mathrm{NaBH}_{4}$ ou solventes orgânicos, e podem acarretar diversos danos ambientais (WANG et al., 2014).

O método de síntese verde tem sido utilizado como uma alternativa simples e viável a procedimentos químicos e métodos físicos (RAMESH, HARIPRASAD e RAGUNATHAN, 2011), devido ao seu baixo custo e por ser "eco friendly" (ambientalmente correto). Dentre os vários materiais naturais utilizados para a síntese de nanopartículas, as plantas parecem ser as melhores opções, pois as nanopartículas produzidas por plantas são mais estáveis e a taxa de produção é rápida (SHARMA et al., 2015). O principal agente ativo de alguns métodos de síntese de nanopartículas metálicas utilizando plantas são os polifenóis (KHARISSOVA et al., 2013). A romã (Punica granatum) é reconhecida por ser uma boa fonte de antioxidantes, os polifenóis são a principal classe de fitoquímicos extraídos a partir de quase todas as partes da romãzeira, mas são mais abundantes nos frutos, principalmente nas cascas (SILVA et al., 2013).

O carvão ativado é admitido como um eficiente adsorvente, devido à sua elevada área superficial e estruturas internas dos poros bem desenvolvidas (KALIJADIS et al.,
2011). Também pode ser utilizado como suporte em reações catalíticas para tratamento de água (VALDÉS e ZAROR, 2006). Os metais são incorporados no carvão por impregnação ou adsorção (HU et al., 1999). O método de impregnação-redução é uma técnica simples e direta em ciência dos materiais para preparação de nanomateriais suportados. Basicamente, ele envolve duas etapas: impregnação e redução. Durante a impregnação, o suporte é imerso na solução aquosa contendo os precursores metálicos desejados. Em seguida, os íons de metal são reduzidos ao estado metálico pela adição de uma solução aquosa de agente redutor (HOLADE et al., 2015).

O principal objetivo deste trabalho foi desenvolver um método verde de impregnação de nanopartículas de óxido de cobre em carvão ativado vegetal para posterior utilização em tratamento de água.

\section{MATERIAIS E MÉTODOS}

Para a síntese das nanopartículas de óxido de cobre foi utilizada metodologia adaptada de Wang et al., 2014. Foram utilizadas soluções de sulfato de cobre a $0,5 \%, 1 \%$ e $1,5 \%$ e extrato de folhas de romã a $60 \mathrm{~g} / \mathrm{L}$. Adicionou-se ao carvão ativado vegetal de coco de dendê, a uma proporção de $2: 1$, o extrato vegetal e a solução de metal. Agitou-se os materiais preparados em incubadora refrigerada com agitação (TE-421 TECNAL), a temperatura ambiente por 36 $\mathrm{h} / 160 \mathrm{rpm}$, e posteriormente secou-os em estufa (SXCR/42 STERILIFER) a $50^{\circ} \mathrm{C}$.

A caracterização dos materiais obtidos consistiu nas análises das imagens de microscopia eletrônica de varredura (MEV) acoplado com análise do espectro de energia dispersiva (EDS) em microscópio eletrônico de varredura SS-550 SUPERSCAN SHIMADZU e de transmissão (MET) em microscópio eletrônico de transmissão JEM1400 JEOL, determinação da área superficial 
por adsorção de $\mathrm{N}_{2}$, utilizando o aparelho Quanta Chrome - Nova 1000 series, cujo funcionamento baseia-se no método B.E.T. (Brunauer-Emmet-Teller) e análise por difratometria de raios-x (DRX) em Difratômetro D6000 Shimadzu.

Os diâmetros das nanopartículas de óxido de cobre foram estimados a partir da equação de Scherrer (1) utilizando os picos de difração mais intensos relacionados aos compostos de cobre.

$D=\frac{K \lambda}{\beta \cos \theta}$

Em que:

D: diâmetro médio das partículas

$\mathrm{K}$ : constante que depende da forma das partículas

$\lambda$ : comprimento de onda da radiação eletromagnética

$\theta$ : ângulo de difração de difração

$\beta$ : largura na metade da altura do pico

\section{RESULTADOS E DISCUSSÃO}

O carvão ativado granular utilizado é produzido a partir do cocô de dendê. Através da fotomicrografia do carvão puro, verificouse que a estrutura superficial é porosa, com poros distribuídos uniformemente ao longo da matriz carbonácea, o que possibilita obter um elevado valor de área superficial como será apresentado mais adiante nos resultados das análises do BET. Após a modificação dos carvões, observou-se por meio das imagens de $\mathrm{MEV}$, que a estrutura superficial permaneceu porosa e foi possível notar o surgimento de pequenas partículas sobre a matriz do carvão, possivelmente devido à presença de nanopartículas de cobre obtidas no processo de impregnação, como mostra a Figura 1:
Figura 1- Fotomicrografias dos carvões ativados puro e modificados com $0,5 \%, 1 \%$ e $1,5 \%$ de $\mathrm{Cu}$.
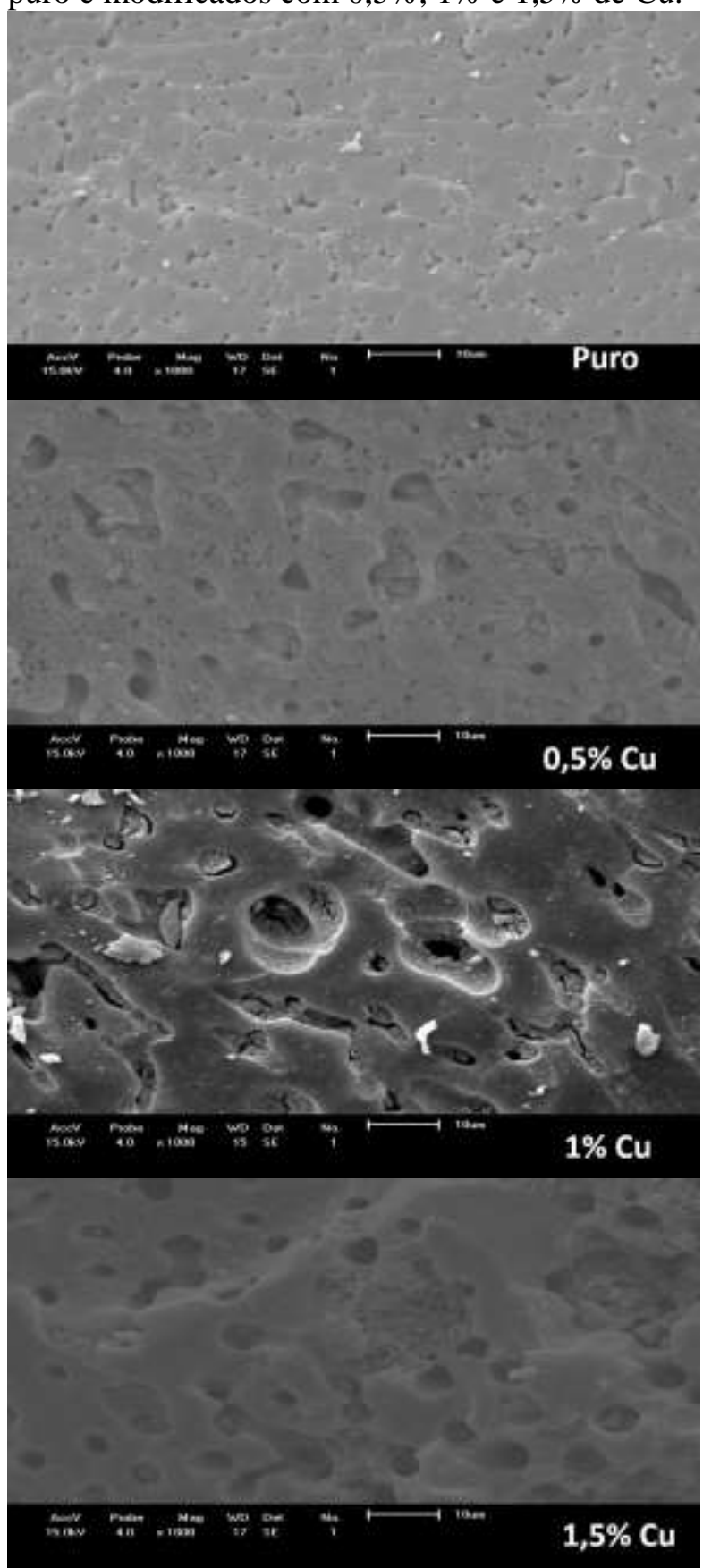

Fonte: Autor (2015)

Não se pode observar claramente diferenças entre os diferentes materiais devido a resolução do equipamento, que permite obter uma escala de 10 micrometros, enquanto espera-se obter partículas de óxido 
de cobre/cobre metálico na faixa de nanômetros.

Apesar das pequenas diferenças observadas nas imagens de MEV, os espectros de EDS obtidos comprovam a presença do elemento cobre nas amostras de carvão ativado impregnado com o metal, o mesmo elemento não foi detectado na amostra de carvão ativado puro, na qual foram encontrados picos de carbono, oxigênio, ouro (devido ao recobrimento da amostra para análise), além dos metais $\mathrm{Al}$, $\mathrm{Si}$ e $\mathrm{Mg}$, característicos de biomassa, visto que o carvão ativado foi produzido a partir do coco de dendê. A Figura 2 mostra esses espectros:

Figura 2 - Espectros de EDS dos carvões puro e impregnados com $0,5 \%, 1 \%$ e $1,5 \%$ de $\mathrm{Cu}$.

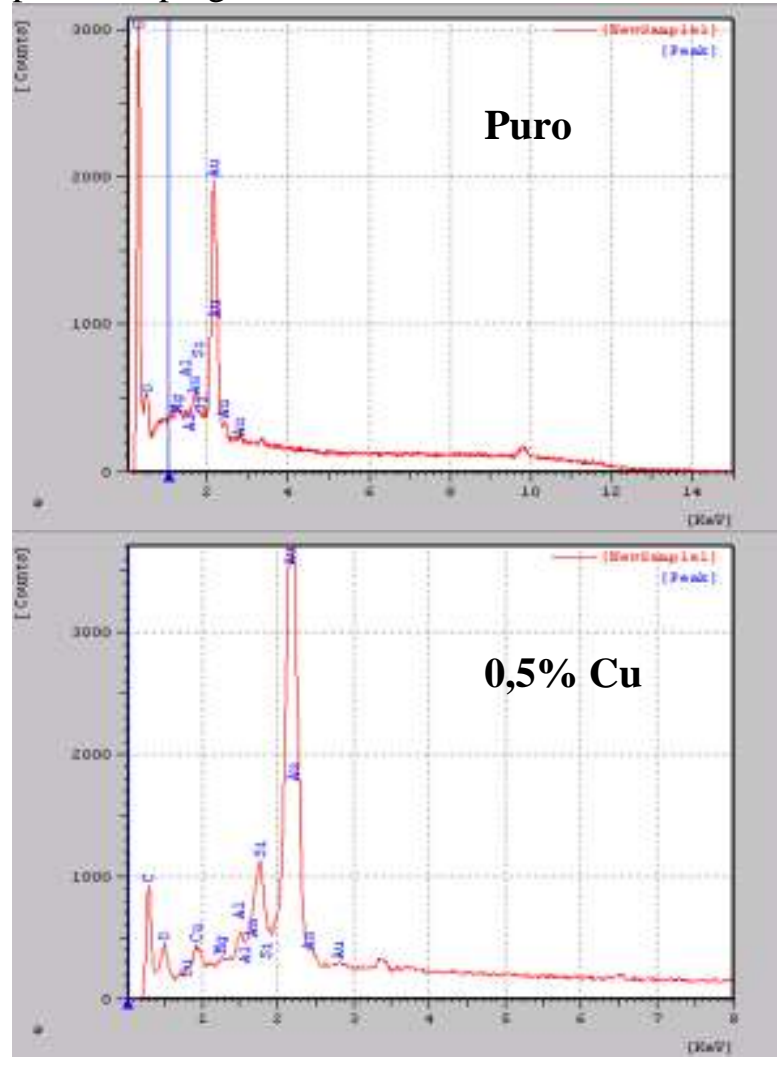

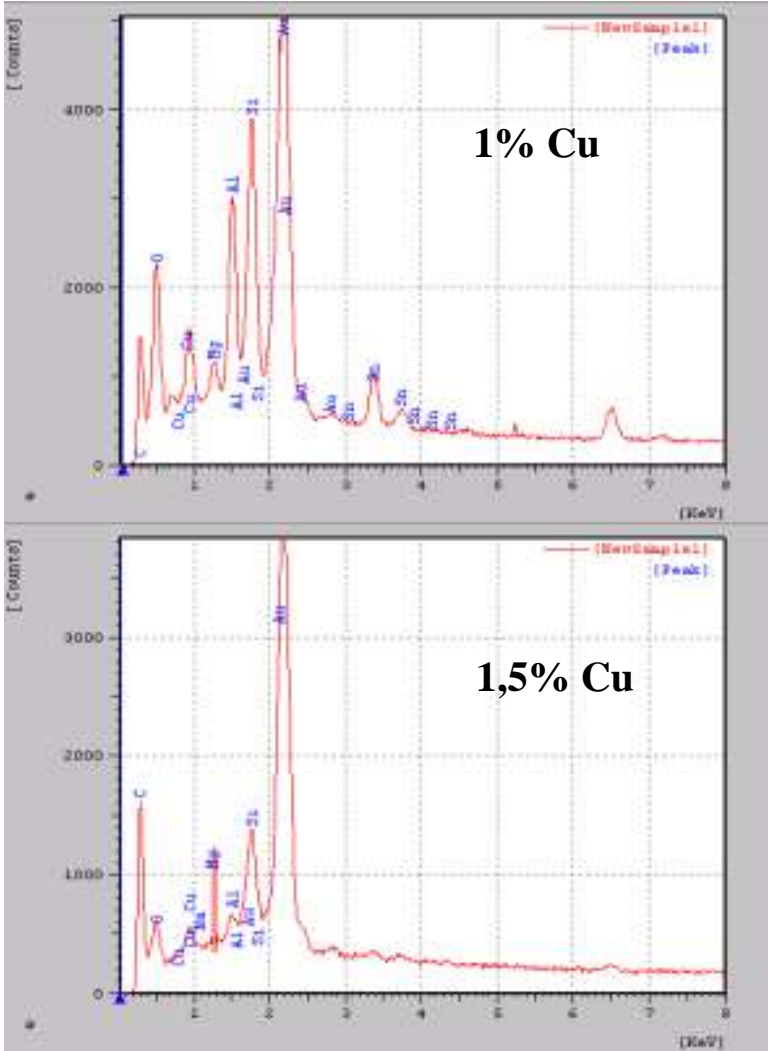

Fonte: Autor (2015)

Para uma melhor caracterização, foram então obtidas imagens de MET, Figura 3, onde pode-se observar a matriz carbonácea, de coloração acinzentada, com partículas de coloração mais escura, características de partículas metálicas, neste caso, nanopartículas de cobre ou de compostos de cobre. 
Figura 3 - MET do carvão impregnado com $0,5 \%, 1 \%$ e $1,5 \%$ de $\mathrm{Cu}$ utilizando extrato de folhas de romã como agente redutor.

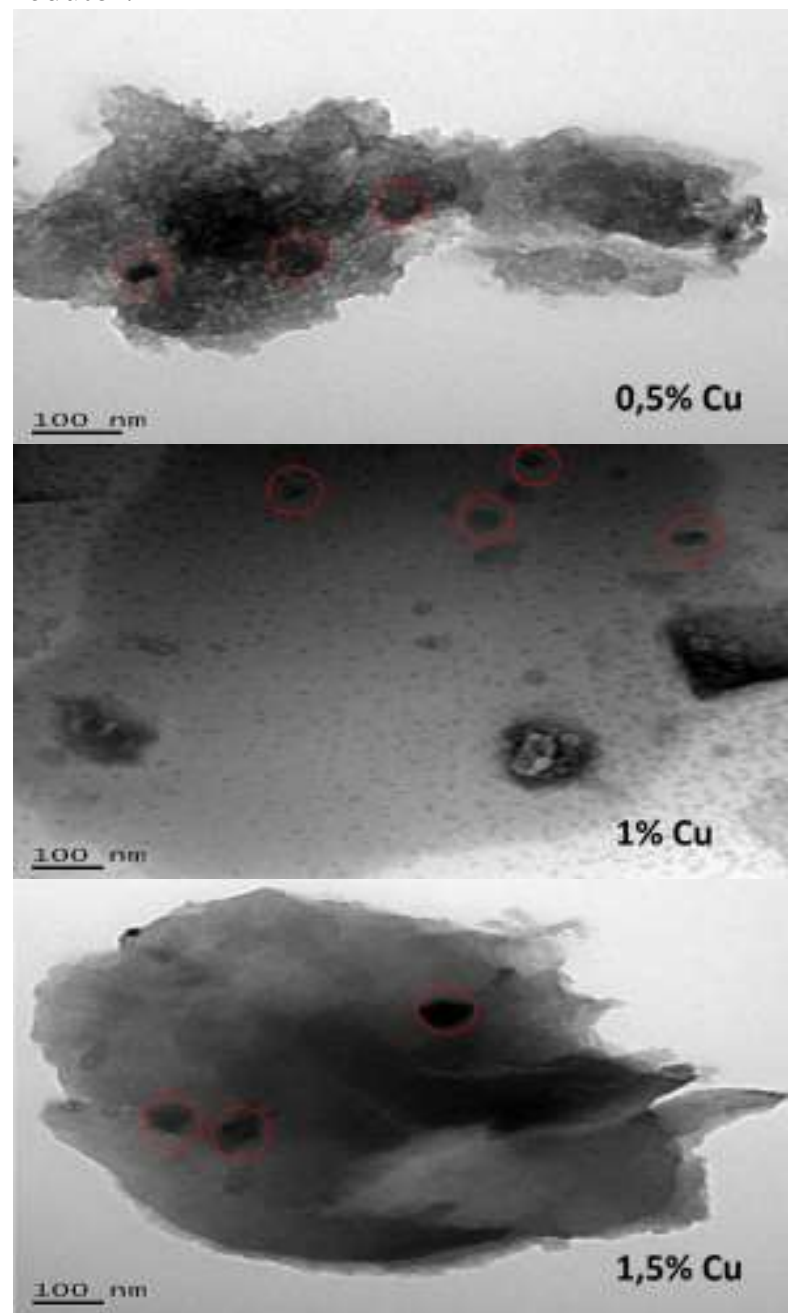

Fonte: Autor (2015)

Os materiais também foram caracterizados texturalmente na análise de BET. Os parâmetros analisados foram: área superficial específica BET $\left(\mathrm{S}_{\mathrm{BET}}\right)$, área de microporos (método $\mathrm{t})\left(\mathrm{S}_{\text {micro }}\right)$, volume de microporos (método $\mathrm{HK})\left(\mathrm{V}_{\text {micro }}\right)$ e $\mathrm{o}$ diâmetro de poros $\left(D_{p}\right)$. Os valores foram obtidos através do programa Quantachrome, como mostra a Tabela 1.
Tabela 1 - Parâmetros da caracterização textural dos carvões puro e impregnados.

\begin{tabular}{lllll}
\hline Material & $\begin{array}{l}\mathrm{S}_{\mathrm{BET}} \\
\left(\mathrm{m}^{2} / \mathrm{g}\right)\end{array}$ & $\begin{array}{l}\mathrm{S}_{\text {micro }} \\
\left(\mathrm{m}^{2} / \mathrm{g}\right)\end{array}$ & $\begin{array}{l}\mathrm{V}_{\text {micro }} \\
\left(\mathrm{cm}^{3} / \mathrm{g}\right)\end{array}$ & $\begin{array}{l}\mathrm{D}_{\mathrm{p}} \\
(\AA)\end{array}$ \\
\hline Puro & 575 & 416 & 0,24 & 12,0 \\
$0,5 \% \mathrm{Cu}$ & 599 & 340 & 0,15 & 10,0 \\
$1 \% \mathrm{Cu}$ & 638 & 348 & 0,15 & 10,5 \\
$1,5 \% \mathrm{Cu}$ & 628 & 321 & 0,14 & 10,4
\end{tabular}

Fonte: Autor (2015)

Pode-se observar que o carvão ativado puro já possui elevada área superficial $\left(\mathrm{S}_{\mathrm{BET}}\right)$ e que essa área aumenta com a adição de cobre utilizado na modificação desse material, o que é muito vantajoso para a adsorção de poluentes. Em contrapartida, o volume e a área dos microporos diminuíram em relação ao carvão puro, pois as nanopartículas de óxido de cobre podem ter causado obstrução parcial destes microporos, visto que o diâmetro de poro, na faixa de $10 \AA$ ou $1 \mathrm{~nm}$, é menor do que o diâmetro estimado das nanopartículas pela equação de Scherrer, como será demonstrado mais adiante. No entanto, a diferença no tamanho do diâmetro de poros entre os carvões não foi expressiva, isso mostra que a impregnação das nanopartículas de óxido de cobre não bloqueia significativamente a entrada e o canal dos poros (PARK et al., 2015).

Por último, apresenta-se a análise dos difratogramas de raios-x, nos quais foi possível observar picos característicos de substâncias cristalinas sobre a matriz amorfa do carvão, como mostra a Figura 4: 
Figura 4- Difratograma de raios-x das amostras de carvão impregnado com nanopartículas de cobre em diferentes concentrações.

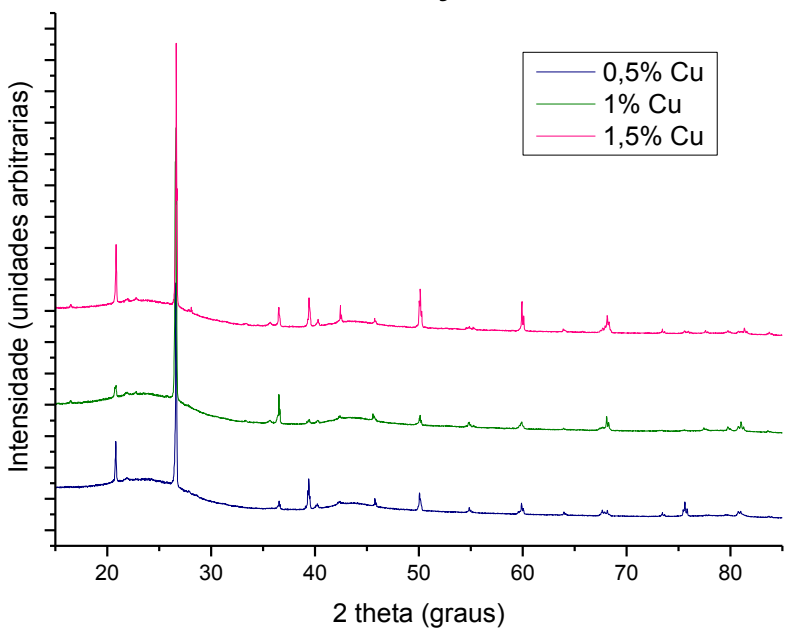

Fonte: Autor (2015)

Analisando esses difratogramas utilizando o banco de dados disponível no software MDI Jade 5 XRD encontrou-se picos relacionados aos compostos de cobre nas angulações de 2 theta igual a $20,76^{\circ} ; 36,71^{\circ}$ e $42,48^{\circ}$ referentes ao composto $\mathrm{CuO}$ (óxido de cobre (II) ou óxido cúprico) e 2 theta igual a $40,20^{\circ}$ e $45,72^{\circ}$ relacionados ao $\mathrm{Cu}_{2} \mathrm{O}$ (óxido de cobre (I) ou óxido cuproso).

Utilizando a equação de Scherrer (1) estimou-se o tamanho médio das nanopartículas de $\mathrm{CuO}$ e $\mathrm{Cu}_{2} \mathrm{O}$ a partir dos picos de difração de $20,76^{\circ}$ e $45,72^{\circ}$, respectivamente, que são mais intensos. Os resultados são apresentados na Tabela 2:

Tabela 2 - Diâmetro médio das nanopartículas de óxidos de cobre sintetizadas pelo método verde.

\section{Diâmetro (nm)}

\begin{tabular}{ccc}
\hline $\begin{array}{c}\text { Amostra de } \\
\text { carvão }\end{array}$ & $\mathrm{CuO}$ & $\mathrm{Cu}_{2} \mathrm{O}$ \\
\hline $0,5 \% \mathrm{Cu}$ & 75 & 159 \\
$1 \% \mathrm{Cu}$ & 61 & 143 \\
$1,5 \% \mathrm{Cu}$ & 76 & 114
\end{tabular}

Fonte: Autor (2015)

Verifica-se na Tabela 2 que o tamanho estimado das nanopartículas de óxido cúprico
$(\mathrm{CuO})$ está entre 61 e $76 \mathrm{~nm}$, enquanto que as nanopartículas de óxido cuproso $\left(\mathrm{Cu}_{2} \mathrm{O}\right)$ medem de 114 a $159 \mathrm{~nm}$. Estes valores estão dentro do que a literatura reporta para o diâmetro das nanopartículas de óxidos de cobre sintetizadas a partir de métodos verdes. Foram encontrados tamanhos de nanopartículas de $\mathrm{CuO}$ de 5 a $10 \mathrm{~nm}$ (NAIKA et al., 2015), 20 a $30 \mathrm{~nm}$ (SHARMA et al., 2015), $46 \mathrm{~nm}$ (SIVARAJ et al., 2014), 140 nm (SANKAR et al., 2014b) e $544 \mathrm{~nm}$ (SANKAR et al., 2014a), enquanto que nanopartículas de $\mathrm{Cu}_{2} \mathrm{O}$ foram relatadas com tamanhos de 30 a $50 \mathrm{~nm}$ (RAMESH et al., 2011), 60 a $80 \mathrm{~nm}$ (GOPALAKRISHNAN et al., 2012) e 100 a $200 \mathrm{~nm}$ (LI, LV e AI, 2015).

\section{CONCLUSÃO}

O método verde de obtenção de nanopartículas de óxido de cobre impregnadas sobre o carvão ativado utilizando extrato das folhas de romã foi eficiente, como foi possível observar nas análises de caracterização realizadas, assegurando uma alternativa mais sustentável na obtenção de carvões impregnados que podem ser utilizados no tratamento de águas, como por exemplo na remoção de contaminantes microbiológicos.

\section{NOMENCLATURA}

BET: Brunauer, Emmet e Teller.

DRX: Difratômetro de Raios-X.

EDS: Espectro de Energia Dispersiva.

MET: Microscopia Eletrônica de Transmissão.

MEV: Microscopia Eletrônica de Varredura.

\section{REFERÊNCIAS}

CARNES, C. L., STIPP, J., KLABUNDE, K. J., BONEVICH, J. Synthesis, characterization and adsorption studies of nanocrystalline 
copper oxide and nickel oxide. Langmuir, v. 18, n. 4, p. 1352-1359, 2002.

CHANG, Y. N., ZHANG, M., XIA, L., ZHANG, J., XING, G. The Toxic Effects and Mechanisms of $\mathrm{CuO}$ and $\mathrm{ZnO}$ Nanoparticles. Materials, v. 5, p. 2850-2871, 2012.

DHAS, N. A., RAJ, C. P., GEDANKEN, A. Synthesis, characterization, and properties of metallic copper nanoparticles. Chemistry of materials, v. 10, n. 5, p. 1446-1452, 1998.

DIZAJ, S. M., LOTFIPOUR, F., BARZEGAR-JALALI, M., ZARRINTAN, M. H., ADIBKIA, K. Antimicrobial activity of the metals and metal oxide nanoparticles. Materials Science and Engineering: $C$, v. 44, p. 278-284, 2014.

FERREIRA, A. J., CEMLYN-JONES, J., CORDEIRO, C. R. Nanoparticles, nanotechnology and pulmonary nanotoxicology. Revista Portuguesa de Pneumologia (English Edition), v. 19, n. 1, p. 28-37, 2013.

GOPALAKRISHNAN, K., RAMESH, C., RAGUNATHAN, V., THAMILSELVAN, M. Antibacterial activity of $\mathrm{Cu}_{2} \mathrm{O}$ nanoparticles on E. coli synthesized from tridax procumbens leaf extract and surface coating with polyaniline. Digest $\mathbf{J}$ Nanomat Biostruct, v. 7, n. 2, p. 833-839, 2012.

HOLADE, Y., SAHIN, N. E., SERVAT, K., NAPPORN, T. W., KOKOH, K. B. Recent Advances in Carbon Supported Metal Nanoparticles Preparation for Oxygen Reduction Reaction in Low Temperature Fuel Cells. Catalysts, v. 5, n. 1, p. 310-348, 2015.

HU, X., LEI, L., CHU, H. P., YUE, P. L. Copper/activated carbon as catalyst for organic wastewater treatment. Carbon, v. 37, n. 4, p. 631-637, 1999.
KALIJADIS, A. M., VUKČEVIĆ, M. M., JOVANOVIĆ, Z. M., LAUŠEVIĆ, Z. V., LAUŠEVIĆ, M. D. Characterisation of surface oxygen groups on different carbon materials by the Boehm method and temperature-programmed desorption. Journal of the Serbian Chemical Society, v. 76, n. 5, p. 757-768, 2011.

KHARISSOVA, O. V., DIAS, H. R., KHARISOV, B. I., PÉREZ, B. O., PÉREZ, V. M. The greener synthesis of nanoparticles. Trends in biotechnology, v. 31, n. 4, p. 240248, 2013.

LI, P., LV, W., AI, S. Green and gentle synthesis of $\mathrm{Cu}_{2} \mathrm{O}$ nanoparticles using lignin as reducing and capping reagent with antibacterial properties. Journal of Experimental Nanoscience, n. ahead-ofprint, p. 1-10, 2015.

LIPPMANN, T., SCHNEIDER, J. R. Topological analyses of cuprite, $\mathrm{Cu}_{2} \mathrm{O}$, using high-energy synchrotron-radiation data. Acta Crystallographica Section A: Foundations of Crystallography, v. 56, n. 6, p. 575-584, 2000.

LIU, Z., BANDO, Y. A novel method for preparing copper nanorods and nanowires. Advanced Materials, v. 15, n. 4, p. 303-305, 2003.

NAIKA, H. R., LINGARAJU, K., MANJUNATH, K., KUMAR, D., NAGARAJU, G., SURESH, D., NAGABHUSHANA, H. Green synthesis of $\mathrm{CuO}$ nanoparticles using Gloriosa superba $\mathrm{L}$. extract and their antibacterial activity. Journal of Taibah University for Science, v. 9, n. 1, p. 7-12, 2015.

PARK, H. S., KODURU, J. R., CHOO, K. H., LEE, B. Activated carbons impregnated with 
iron oxide nanoparticles for enhanced removal of bisphenol $\mathrm{A}$ and natural organic matter. Journal of hazardous materials, v. 286, p. 315-324, 2015.

RAMESH, C. HARIPRASAD, M. RAGUNATHAN, V. Effect of Arachis hypogaea L. leaf extract on barfoed's solution; green synthesis of $\mathrm{Cu} 2 \mathrm{O}$ nanoparticles and its antibacterial effect. Current Nanoscience, v. 7, n. 6, p. 995-999, 2011.

SANKAR, R., MAHESWARI, R., KARTHIK, S., SHIVASHANGARI, K. S., \& RAVIKUMAR, V. Anticancer activity of Ficus religiosa engineered copper oxide nanoparticles. Materials Science and Engineering: C, v. 44, p. 234-239, 2014a.

SANKAR, R., MANIKANDAN, P., MALARVIZHI, V., FATHIMA, T., SHIVASHANGARI, K. S., RAVIKUMAR, V. Green synthesis of colloidal copper oxide nanoparticles using Carica papaya and its application in photocatalytic dye degradation. Spectrochimica Acta Part A: Molecular and Biomolecular Spectroscopy, v. 121, p. 746-750, 2014b.

SHARMA, J. K., AKHTAR, M. S., AMEEN, S., SRIVASTAVA, P., SINGH, G. Green synthesis of $\mathrm{CuO}$ nanoparticles with leaf extract of Calotropis gigantea and its dyesensitized solar cells applications. Journal of Alloys and Compounds, v. 632, p. 321-325, 2015.

SILVA, J. A. T., RANAC, T. S., NARZARYD, D., VERMAE, N., MESHRAMF, D. T., RANADEG, S. A. Pomegranate biology and biotechnology: A review. Scientia Horticulturae, v. 160, p. 85-107, 2013.

SIVARAJ, R., RAHMAN, P. K., RAJIV, P., SALAM, H. A., \& VENCKATESH, R.
Biogenic copper oxide nanoparticles synthesis using Tabernaemontana divaricate leaf extract and its antibacterial activity against urinary tract pathogen. Spectrochimica Acta Part A: Molecular and Biomolecular Spectroscopy, v. 133, p. 178-181, 2014.

TAN, S., ZOU, W., JIANG, F., TAN, S., LIU, Y., YUAN, D. Facile fabrication of coppersupported ordered mesoporous carbon for antibacterial behavior. Materials Letters, v. 64, n. 20, p. 2163-2166, 2010.

VALDÉS, H., ZAROR, C. A. Heterogeneous and homogeneous catalytic ozonation of benzothiazole promoted by activated carbon: kinetic approach. Chemosphere, v. 65, n. 7, p. 1131-1136, 2006.

VITULLI, G., BERNINI, M., BERTOZZI, S., PITZALIS, E., SALVADORI, P., COLUCCIA, S., MARTRA, G. Nanoscale copper particles derived from solvated $\mathrm{Cu}$ atoms in the activation of molecular oxygen. Chemistry of materials, v. 14, n. 3 , p. 11831186, 2002.

WANG, T., LIN, J., CHEN, Z., MEGHARAJ, M., NAIDU, R. Green synthesized iron nanoparticles by green tea and eucalyptus leaves extracts used for removal of nitrate in aqueous solution. Journal of Cleaner Production, v. 83, p. 413-419, 2014.

\section{AGRADECIMENTOS}

Ao CNPQ pelo apoio financeiro concedido à este projeto. 